\title{
Chronic conditions in adolescents (Review)
}

\author{
MINGWEI JIN, QI AN and LEI WANG \\ Department of Pediatric Internal Medicine, Xuzhou Children's Hospital, Xuzhou, Jiangsu 221002, P.R. China
}

Received February 27, 2017; Accepted May 22, 2017

DOI: $10.3892 / \mathrm{etm} .2017 .4526$

\begin{abstract}
The health problems related to the nervous system are on rise in young infants leading to high mortality amongst this age group. A chronic medical condition (CC) is present in this age group to the tune of $10-20 \%$. We searched the electronic database PubMed for pre-clinical as well as clinical controlled trials reporting variable chronic conditions especially in pediatric patients. Most of these reports revealed that type 1 diabetes mellitus is the most common $\mathrm{CC}$ in young infants. In female patients, metabolic control is often disturbed during $\mathrm{CC}$ in this age group. Poor metabolism regulation often results in long-term complications, including cognitive disorders. In cognitive disorders, memory loss and learning problems are the most among adolescents. Executive problems are observed to be associated with low physical activities. The review article concludes that knowledge about factors influencing treatment adherence is crucial in chronically ill infants. Further, we should focus on protective factors in order to prevent health risk behavior.
\end{abstract}

\section{Contents}

1. Introduction

2. Chronic conditions in adolescents

3. Type 1 diabetes in adolescents

4. Long-term complications from T1DM

5. Executive functioning problems and ADHD

6. The brain and ADHD

7. Diabetes and neurodevelopmental/neuropsychiatric conditions

8. Conclusion

\section{Introduction}

Mortality rates are higher among adolescents than among younger children $(1,2)$ and mental health problems among

Correspondence to: Dr Qi An, Department of Pediatric Internal Medicine, Xuzhou Children's Hospital, 18 Sudibei Road, Xuzhou, Jiangsu 221002, P.R. China

E-mail: aiqiangel@yeah.net

Key words: pediatric, mental problems, chronic conditions adolescents are increasing day by day (3). The increase in mental health problems is related with poor school achievements and high unemployment rates. It has been shown that positive school environments promote adolescent health and prevent health-risk behavior (4).

The experimental behavior could be considered a normal part of adolescent development. However, sometimes it leads to risky behavior that might compromise health, quality of life, or life itself (5). For instance, early sexual activities, unsafe sexual practices, drug abuse and antisocial behaviour could put health at risk. Protective factors, on the other hand, can be defined as conditions that improve the resistance to risk factors and disorders (6) and they can be identified at multiple levels in adolescents: the individual, the family and the community (7). The concept 'social determinants of health' encompasses these levels as well as the national level (8). Worldwide, the strongest determinants of adolescent health are national wealth and access to education. Improving access to education and employment for young people as well as reducing the risk of transport-related injury are suggested as the most effective interventions in order to improve adolescent health worldwide. Moreover, safe and supportive families and schools together with positive and supportive peers are crucial to help adolescents develop their full potential.

\section{Chronic conditions in adolescents}

A chronic illness, defined as a disability interfering with normal life and/or demanding treatment for $\geq 3$ months during a year (9). Asthma, type 1 diabetes mellitus (T1DM), epilepsy and inflammatory bowel disease are all examples of chronic illnesses prevalent in paediatric patients. Neurodevelopmental conditions are also common in children and adolescents. The worldwide prevalence of attention-deficit hyperactivity disorder (ADHD) among school children has been estimated to about $5 \%$ (10) and about $1 \%$ of Swedish school children are diagnosed with autism spectrum disorders (ASD) (11) and Tourette syndrome (9) respectively. However, neurodevelopmental problems commonly co-exist in children and adolescents and when this overlap is taken into account, it has been reported that approximately $7-10 \%$ of young people suffer from a neurodevelopmental problem (11). The overall prevalence of chronic conditions in childhood and adolescents should thus be estimated to $15-20 \%$. Some of these conditions require daily and lifelong medical treatment. Other conditions entail social problems, resulting in difficulties exploring life, while other adolescents with chronic conditions participate in 
risk-taking behavior (10). In fact, increasing data indicate that adolescents with chronic conditions are engaged to the same extent or even more in health-risk behavior compared with their healthy counterparts $(12,13)$. Further, there is evidence that health-risk behavior tend to cluster together $(14,15)$. Due to this, young people with chronic conditions have double disadvantage during their adolescence (16). Moreover, adolescents with disabilities are less exposed to protective factors (17) and children with chronic conditions are more exposed to bullying (18), have fewer contacts with peers and more emotional problems than healthy counterparts (19). Furthermore, a study in a recent past indicated an association between chronic conditions in children and lower family socioeconomic status, compared to healthy peers (20).

\section{Type 1 diabetes in adolescents}

Getting T1DM during adolescence is complicated and related to poorer long-term metabolic control, compared to patients getting diabetes $<10$ years of age $(21,22)$. Also, metabolic control often deteriorates during adolescence (23). However, two distinct trajectories of metabolic control across adolescence have been identified: moderate control with slight deterioration (representing a majority of adolescent patients) and poor control with rapid deterioration ( $<10 \%$ of patients). Adolescents with poor and rapidly deteriorating metabolic control reported lower paternal monitoring and frequency of help with diabetes management, lower functional autonomy, and lower self-control than others. Patients in this group were also more likely to report diabetes-related emergency room visits and diabetes-related hospitalizations.

The metabolic deterioration during adolescence is especially prevalent in girls (24). However, there is a gender difference in HbA1c already at diagnosis (25) and at follow-up where girls present higher values than boys. One reason for this phenomenon in adolescent girls can be increased GH-secretion, which induces insulin resistance (26). Other reasons for poor metabolic control in adolescents have been speculated to be irregular meal (27) and exercise patterns (28), poor adherence to treatment regimens (29) as well as risk-taking behavior.

Risk-taking behaviours are baneful in patients with T1DM. Tobacco smoking in patients with T1DM is associated with an increased risk for premature death by cardiovascular disease (30). Alcohol inhibits gluconeogenesis in the liver, which might result in severe hypoglycaemia. Ingestion of carbohydrates and measuring of blood glucose before sleep can prevent this (31). Further, cannabis smoking can first lead to excess snacking and then to loss of appetite. Drug use, in general, also alters brain functions, increasing the risk for mistakes with diabetes management. Adolescents with T1DM should be encouraged to refrain from smoking, binge drinking and use of other drugs.

Sexual activity in adolescents with T1DM must be specially acknowledged. Focus should be put on avoiding hypoglycaemia after intercourse as well as optimizing metabolic control in case of pregnancy. Poor metabolic control during pregnancy increases the risk for congenital malformations and foetal death (32). Contraceptives should be advocated in the group of sexually active adolescents with T1DM. Condoms, newer oral contraceptives (OCs) with lower oestrogen doses and newer progesterones as well as long-acting reversible contraceptives (including intrauterine devices and implantable rods) are recommended.

\section{Long-term complications from T1DM}

Patients with T1DM and good metabolic control have a double risk for death from any cause or from cardiovascular disease, compared to controls without T1DM (33). In patients with poorer metabolic control this risk is even higher. With HbAlc $\geq 83 \mathrm{mmol} / \mathrm{mol}$ the adjusted hazard ratio is 8.51 for death from any cause and 10.46 for death by cardiovascular disease as compared to controls without T1DM (34). Recently it has been shown that young adults with mean $\mathrm{HbAlc}>78 \mathrm{mmol} / \mathrm{mol}$ had a significantly higher proportion of retinopathy, microalbuminuria and/or macroalbuminuria compared to the group with HbAlc below $57 \mathrm{mmol} / \mathrm{mol}$. Other studies show that HbA1c exceeding $70 \mathrm{mmol} / \mathrm{mol}$ is associated with long-term complications, such as cardiovascular disease and nephropathy (35) while these complications are not seen when long-term mean $\mathrm{HbAlc}$ is kept below $60 \mathrm{mmol} / \mathrm{mol}$ (36).

The main complications of T1DM are micro- and macrovascular diseases, manifested as retinopathy, nephropathy, neuropathy, and cardiovascular disease (37). These might result in visual impairments and blindness, renal failure and hypertension, pain, muscle weakness, autonomic dysfunction, cardiac disease, peripheral vascular disease and stroke. Recently cognitive dysfunctions, based on neuropsychological testing, were reported to be five times more common in adults with T1DM, compared to adults without diabetes (38). Cognitive problems are thus discussed as one of the major complications to T1DM as well.

\section{Executive functioning problems and ADHD}

Executive functions serve to organize and control thought and behavior (39) and are often defined as the 'conductor' of the brain. Key elements of executive functions include planning and organization abilities, anticipation, initiation of activity, different aspects of attention, impulse control and self-regulation, utilization of feedback, selection of efficient problem-solving strategies, mental flexibility and working memory (40). Functional magnetic resonance imaging and positron emission tomography have related brain networks involved in executive functioning to the prefrontal cortex of the brain.

Impaired executive functioning is one of the characteristics of ADHD (41). Executive functioning problems are also commonly occurring in individuals with impaired intellectual abilities (42), in ASD (43) as well as in patients with anxiety and depression (44). These neurodevelopmental disorders commonly co-exist in children and adolescents, which is why the acronym ESSENCE (Early Symptomatic Syndromes Eliciting Neurodevelopmental Clinical Examinations) has been developed. The concept of ESSENCE advocates a holistic and multidisciplinary approach to patients presenting with early neurodevelopmental symptoms.

Executive functioning problems are presented on a spectrum, ranging from mild problems to more severe, compatible with the diagnosis of ADHD (45). There are 18 symptom criteria 
of ADHD, according to the DSM-IV (46) and DSM-5 (47). The 3 subtypes/presentations of ADHD are: the combined, the inattentive and the hyperactive/impulsive type/presentation. At least 6 out of 9 symptoms in each domain have to be present in order to fulfill the diagnostic criteria for ADHD. The new DSM-5 states that in young people from the age of $\geq 17$ and $\geq 5$ symptoms are required. The symptoms should be present before 12 years of age, be clinically significant in $\geq 2$ different environments and cause functional disabilities during $\geq 6$ months. The heritability of ADHD is around $76 \%$, suggesting a strong genetic role in ADHD aetiology (48). Thus parents of patients with ADHD are likely to carry the same condition. Moreover, boys are more frequently diagnosed with ADHD during childhood (49) and it is discussed that girls' executive problems frequently are unnoticed and undiagnosed (50). In adolescents with ADHD, time perception is often affected. Moreover, adolescents and adults with ADHD are at heightened risk of drug abuse (51) and antisocial behavior (52).

Clinical guidelines for the treatment of children and adolescents with ADHD recommend the use of multimodal treatment consisting of behavioral interventions, such as parent management training and teacher consultations as well as pharmacological treatment (53). Behavioral interventions include increased support from adults in many daily life situations; reminders, help to organize tasks, get started, follow and complete tasks as well as help to find alternative solutions when required (54). This support is required both in schools and during leisure time (55). The most common pharmacological treatment is stimulant-medication (55). The latter has been shown to prevent risk-behavior such as criminality (56).

\section{The brain and ADHD}

The brain development is often altered in patients with ADHD. This observation was further confirmed by imaging studies of ADHD patients that revealed involvement of the frontal lobes in developmental delay (57). The development of parietal lobes, basal ganglia, corpus callosum and cerebellum are also altered. Functional magnetic resonance imaging studies reveal a hypoactivation of frontoparietal networks, involving executive functions, and hypoactivation of ventral networks, involving attention, in children with ADHD (58). However, there were also indications of hyperactivation of regions in the ventral network, which might support the symptom of distractibility in ADHD. Moreover, children with ADHD have been found to have a delayed striatal development (59). In youths and adults with ADHD striatal activation is also low (60), yielding a suppressed reward system. However, the striatal activity is increased with stimulant-medication, which also improves cortical development in adolescents with ADHD (61).

\section{Diabetes and neurodevelopmental/neuropsychiatric conditions}

Mild cognitive problems are reported in both children (62) and adults (63) with T1DM. Working memory and other executive functions are particularly affected (64). These cognitive dysfunctions have been related to an early onset of the disease and to a history of hypoglycaemic seizures but not to long-term metabolic control $(65,66)$. However, there are studies in adults reporting an association between chronic hyperglycaemia and cognitive dysfunctions (67), while another study reveals a lack of correlation between severe hypoglycaemia or ketoacidosis and cognitive problems in children with T1DM (68). The diathesis theory suggests that the young brain may be harmed by hyperglycaemia early in life, which confers a vulnerability to insults, such as hypoglycaemia, later in life (69). Testing with brief cognitive tests several times a day during 4-6 weeks in school children with T1DM have revealed decreased mental efficacy during spontaneously occurring acute hypo- and hyperglycaemic episodes (70).

Magnetic resonance imaging studies have shown that patients with T1DM have morphological changes in the grey and white matter of the brain. However, the CNS changes in adolescents are subtle and their functional significance uncertain (71). In this context it is noteworthy that ketoacidosis at onset of T1DM has been found to result in morphologic and functional brain changes, associated with adverse moderate neurocognitive outcomes (72).

A number of studies report an increased risk of psychiatric disorders (73), including ADHD (74), in adolescents with T1DM. This is found particularly six months after disease onset but also later in life. However, the association between ADHD and diabetes is debated and it has been demonstrated that ADHD is associated with type 2 but not with type 1 diabetes (75). Although conflicting results in the relationship between ADHD and T1DM, executive problems will yield specific difficulties for patients with T1DM. The treatment of T1DM requires regular insulin injections and dose adjustments in relation to carbohydrate content of the meal as well as planned or accomplished physical activity. This is demanding and requires good cognitive skills. Earlier studies of children with T1DM demonstrate an association between good executive functions, treatment adherence and consequent good metabolic control (76). Good metabolic control has also been associated with lower impulsiveness when compared to patients with poor metabolic control (77).

\section{Conclusion}

Chronic conditions in adolescents are associated with few protective factors and clustered health-risk behavior. The combination of chronic conditions and low numbers of protective factors are often hazardous and associated with an increased risk of clustered health-risk behavior. Moreover, in cases with the presence of ADHD, the pattern of few protective factors and clustering of health-risk behavior among adolescents with chronic conditions is aggregated. Further, ADHD is common among adolescents with other chronic conditions, particularly neurological conditions.

\section{References}

1. Viner RM, Coffey C, Mathers C, Bloem P, Costello A, Santelli J and Patton GC: 50-year mortality trends in children and young people: a study of 50 low-income, middle-income, and high-income countries. Lancet 377: 1162-1174, 2011.

2. Davletov K, McKee M, Berkinbayev S, Battakova Z, Zhussupov B, Amirov B, Junusbekova G and Rechel B: Ethnic differences in all-cause mortality rates in Kazakhstan. Public Health 133: 57-62, 2016 
3. Inchley J, Currie D, Young T, Samdal O, Torsheim T, Augustson L, Mathison F, Aleman-Diaz A, Molcho M, Weber M and Barnekow V (eds): Growing up unequal: gender and socioeconomic differences in young people's health and well-being. Health Behaviour in School-aged Children (HBSC) study: international report from the 2013/2014 survey. WHO Regional Office for Europe, Copenhagen, 2016.

4. Patton GC, Bond L, Carlin JB, Thomas L, Butler H, Glover S, Catalano R and Bowes G: Promoting social inclusion in schools: a group-randomized trial of effects on student health risk behavior and well-being. Am J Public Health 96: 1582-1587, 2006.

5. Jessor R: Risk behavior in adolescence: a psychosocial framework for understanding and action. J Adolesc Health 12: 597-605, 1991

6. Coie JD, Watt NF, West SG, Hawkins JD, Asarnow JR, Markman HJ, Ramey SL, Shure MB and Long B: The science of prevention. A conceptual framework and some directions for a national research program. Am Psychol 48: 1013-1022, 1993.

7. Patterson $J$ and Blum RW: Risk and resilience among children and youth with disabilities. Arch Pediatr Adolesc Med 150: 692-698, 1996.

8. Viner RM, Ozer EM, Denny S, Marmot M, Resnick M, Fatusi A and Currie C: Adolescence and the social determinants of health. Lancet 379: 1641-1652, 2012 .

9. Westbom L and Kornfält R: Chronic illness among children in a total population. An epidemiological study in a Swedish primary health care district. Scand J Soc Med 15: 87-97, 1987.

10. Polanczyk G, de Lima MS, Horta BL, Biederman J and Rohde LA: The worldwide prevalence of ADHD: a systematic review and metaregression analysis. Am J Psychiatry 164: 942-948, 2007.

11. Gillberg C: The ESSENCE in child psychiatry: early symptomatic syndromes eliciting neurodevelopmental clinical examinations. Res Dev Disabil 31: 1543-1551, 2010.

12. Sawyer SM, Drew S, Yeo MS and Britto MT: Adolescents with a chronic condition: challenges living, challenges treating. Lancet 369: 1481-1489, 2007.

13. Valencia LS and Cromer BA: Sexual activity and other high-risk behaviors in adolescents with chronic illness: a review. J Pediatr Adolesc Gynecol 13: 53-64, 2000.

14. Rhee D, Yun SC and Khang YH: Co-occurrence of problem behaviors in South Korean adolescents: findings from Korea Youth Panel Survey. J Adolesc Health 40: 195-197, 2007.

15. Surís JC, Michaud PA, Akre C and Sawyer SM: Health risk behaviors in adolescents with chronic conditions. Pediatrics 122 e1113-e1118, 2008

16. Sawyer S, Drew S and Duncan R: Adolescents with chronic disease - the double whammy. Aust Fam Physician 36: 622-627, 2007.

17. Svetaz MV, Ireland M and Blum R: Adolescents with learning disabilities: risk and protective factors associated with emotional well-being: findings from the National Longitudinal Study of Adolescent Health. J Adolesc Health 27: 340-348. 2000

18. Lucas S, Jernbro C, Tindberg Y and Janson S: Bully, bullied and abused. Associations between violence at home and bullying in childhood. Scand J Public Health 44: 27-35, 2016.

19. Westbom L: Well-being of children with chronic illness. A population-based study in a Swedish primary care district. Acta Paediatr 81: 625-629, 1992

20. Westbom L: Impact of chronic illness in children on parental living conditions. A population-based study in a Swedish primary care district. Scand J Prim Health Care 10: 83-90, 1992.

21. Clements MA, Lind M, Raman S, Patton SR, Lipska KJ, Fridlington AG, Tang F, Jones PG, Wu Y, Spertus JA, et al: Age at diagnosis predicts deterioration in glycaemic control among children and adolescents with type 1 diabetes. BMJ Open Diabetes Res Care 2: e000039, 2014.

22. Noorani M, Ramaiya K and Manji K: Glycaemic control in type 1 diabetes mellitus among children and adolescents in a resource limited setting in Dar es Salaam - Tanzania. BMC Endocr Disord 16: 29, 2016.

23. King PS, Berg CA, Butner J, Drew LM, Foster C, Donaldson D, Murray M, Swinyard M and Wiebe DJ: Longitudinal trajectories of metabolic control across adolescence: associations with parental involvement, adolescents' psychosocial maturity, and health care utilization. J Adolesc Health 50: 491-496, 2012.

24. Dabadghao P, Vidmar S and Cameron FJ: Deteriorating diabetic control through adolescence-do the origins lie in childhood? Diabet Med 18: 889-894, 2001

25. Hanberger L, Åkesson K and Samuelsson U: Glycated haemoglobin variations in paediatric type 1 diabetes: the impact of season, gender and age. Acta Paediatr 103: 398-403, 2014.
26. Halldin MU, Brismar K, Tuvemo T and Gustafsson J: Insulin sensitivity and lipolysis in adolescent girls with poorly controlled type 1 diabetes: effect of anticholinergic treatment. Clin Endocrinol (Oxf) 57: 735-743, 2002.

27. Webb KL, Dobson AJ, O'Connell DL, Tupling HE, Harris GW, Moxon JA, Sulway MJ and Leeder SR: Dietary compliance among insulin-dependent diabetics. J Chronic Dis 37: 633-643, 1984.

28. Loman DG and Galgani CA: Physical activity in adolescents with diabetes. Diabetes Educ 22: 121-125, 1996.

29. Morris AD, Boyle DI, McMahon AD, Greene SA, MacDonald TM and Newton RW: Adherence to insulin treatment, glycaemic control, and ketoacidosis in insulin-dependent diabetes mellitus. The DARTS/MEMO Collaboration. Diabetes Audit and Research in Tayside Scotland. Medicines Monitoring Unit. Lancet 350: $1505-1510,1997$.

30. Haire-Joshu D, Glasgow RE and Tibbs TL; American Diabetes Association: Smoking and diabetes. Diabetes Care 27 (Suppl 1): S74-S75, 2004

31. Cameron FJ, Amin R, de Beaufort C, Codner E and Acerini CL; International Society for Pediatric and Adolescent Diabetes: ISPAD Clinical Practice Consensus Guidelines 2014. Diabetes in adolescence. Pediatr Diabetes 15 (Suppl 20): 245-256, 2014.

32. Negrato CA, Mattar R and Gomes MB: Adverse pregnancy outcomes in women with diabetes. Diabetol Metab Syndr 4: 41, 2012.

33. Lind M, Svensson AM, Kosiborod M, Gudbjörnsdottir S, Pivodic A, Wedel H, Dahlqvist S, Clements M and Rosengren A: Glycemic control and excess mortality in type 1 diabetes. N Engl J Med 371: 1972-1982, 2014.

34. Anderzén J, Samuelsson U, Gudbjörnsdottir S, Hanberger L and Åkesson K: Teenagers with poor metabolic control already have a higher risk of microvascular complications as young adults. J Diabetes Complications 30: 533-536, 2016.

35. Nordwall M, Arnqvist HJ, Bojestig M and Ludvigsson J: Good glycemic control remains crucial in prevention of late diabetic complications - the Linköping Diabetes Complications Study. Pediatr Diabetes 10: 168-176, 2009.

36. Nordwall M, Abrahamsson M,Dhir M,Fredrikson M,Ludvigsson J and Arnqvist HJ: Impact of HbA1c, followed from onset of type 1 diabetes, on the development of severe retinopathy and nephropathy: the VISS Study (Vascular Diabetic Complications in Southeast Sweden). Diabetes Care 38: 308-315, 2015.

37. Donaghue KC, Wadwa RP, Dimeglio LA, Wong TY, Chiarelli F, Marcovecchio ML, Salem M, Raza J, Hofman PL and Craig ME; International Society for Pediatric and Adolescent Diabetes: ISPAD Clinical Practice Consensus Guidelines 2014. Microvascular and macrovascular complications in children and adolescents. Pediatr Diabetes 15 (Suppl 20): 257-269, 2014.

38. Nunley KA, Rosano C, Ryan CM, Jennings JR, Aizenstein HJ, Zgibor JC, Costacou T, Boudreau RM, Miller R, Orchard TJ, et al: Clinically relevant cognitive impairment in middle-aged adults with childhood-onset type 1 diabetes. Diabetes Care 38: 1768-1776, 2015

39. Stuss DT and Alexander MP: Executive functions and the frontal lobes: a conceptual view. Psychol Res 63: 289-298, 2000.

40. Gioia GA, Isquith PK, Guy SC and Kenworthy L: Behavior rating inventory of executive function. Child Neuropsychol 6: 235-238, 2000.

41. Lahey BB, Applegate B, McBurnett K, Biederman J, Greenhill L, Hynd GW, Barkley RA, Newcorn J, Jensen P, Richters J, et al: DSM-IV field trials for attention deficit hyperactivity disorder in children and adolescents. Am J Psychiatry 151: 1673-1685, 1994.

42. Lindblad I, Gillberg C and Fernell E: ADHD and other associated developmental problems in children with mild mental retardation. The use of the 'Five-To-Fifteen' questionnaire in a population-based sample. Res Dev Disabil 32: 2805-2809, 2011.

43. Ozonoff S, Pennington BF and Rogers SJ: Executive function deficits in high-functioning autistic individuals: relationship to theory of mind. J Child Psychol Psychiatry 32: 1081-1105, 1991.

44. Castaneda AE, Tuulio-Henriksson A, Marttunen M, Suvisaari J and Lönnqvist J: A review on cognitive impairments in depressive and anxiety disorders with a focus on young adults. J Affect Disord 106: 1-27, 2008.

45. Barkley RA, Edwards G, Laneri M, Fletcher K and Metevia L: Executive functioning, temporal discounting, and sense of time in adolescents with attention deficit hyperactivity disorder (ADHD) and oppositional defiant disorder (ODD). J Abnorm Child Psychol 29: 541-556, 2001. 
46. American Psychiatric Association: Diagnostic and Statistical Manual of Mental Disorders (DSM-IV). 4th edition. Washington, DC, 1994.

47. American Psychiatric Association: Diagnostic and Statistical Manual of Mental Disorders (DSM-5). 5th edition. Washington, DC, 2013.

48. Akutagava-Martins GC, Rohde LA and Hutz MH: Genetics of attention-deficit/hyperactivity disorder: an update. Expert Rev Neurother 16: 145-156, 2016.

49. Kopp S and Gillberg C: Swedish child and adolescent psychiatric out-patients - a five-year cohort. Eur Child Adolesc Psychiatry 12: 30-35, 2003.

50. Kopp S, Kelly KB and Gillberg C: Girls with social and/or attention deficits: a descriptive study of 100 clinic attenders. J Atten Disord 14: 167-181, 2010.

51. Weinberg NZ, Rahdert E, Colliver JD and Glantz MD: Adolescent substance abuse: a review of the past 10 years. J Am Acad Child Adolesc Psychiatry 37: 252-261, 1998.

52. Ginsberg Y, Hirvikoski T and Lindefors N: Attention deficit hyperactivity disorder (ADHD) among longer-term prison inmates is a prevalent, persistent and disabling disorder. BMC Psychiatry 10: 112, 2010.

53. Kendall T, Taylor E, Perez A and Taylor C; Guideline Development Group: Diagnosis and management of attention-deficit/hyperactivity disorder in children, young people, and adults: summary of NICE guidance. BMJ 337: a1239, 2008.

54. Gillberg C, Fernell E and Råstam Bergström M: Barn- och ungdomspsykiatri. 3rd edition. Natur \& Kultur, Stockholm, 2015 (In Swedish)

55. oemaeus A: StĞd till Äarn, ungdomar och vuñna med adhd - ett âunsâapsstGd., OM14. Socialstyrelsen, Stockholm, 2014 (In Swedish). http://www.socialstyrelsen.se/publikationer2014/2014-10-42.

56. Ginsberg Y, Långström N, Larsson $\mathrm{H}$ and Lindefors $\mathrm{N}$ : Long-term treatment outcome in adult male prisoners with attention-deficit/hyperactivity disorder: three-year naturalistic follow-up of a 52-week methylphenidate trial. J Clin Psychopharmacol 35: 535-543, 2015.

57. Giedd JN and Rapoport JL: Structural MRI of pediatric brain development: what have we learned and where are we going? Neuron 67: 728-734, 2010.

58. Cortese S, Kelly C, Chabernaud C, Proal E, Di Martino A, Milham MP and Castellanos FX: Toward systems neuroscience of ADHD: a meta-analysis of 55 fMRI studies. Am J Psychiatry 169: 1038-1055, 2012

59. Durston S, Tottenham NT, Thomas KM, Davidson MC, Eigsti IM, Yang Y, Ulug AM and Casey BJ: Differential patterns of striatal activation in young children with and without ADHD. Biol Psychiatry 53: 871-878, 2003

60. Epstein JN, Casey BJ, Tonev ST, Davidson MC, Reiss AL, Garrett A, Hinshaw SP, Greenhill LL, Glover G, Shafritz KM, et al: ADHD- and medication-related brain activation effects in concordantly affected parent-child dyads with ADHD. J Child Psychol Psychiatry 48: 899-913, 2007.

61. Shaw P, Sharp WS, Morrison M, Eckstrand K, Greenstein DK, Clasen LS, Evans AC and Rapoport JL: Psychostimulant treatment and the developing cortex in attention deficit hyperactivity disorder. Am J Psychiatry 166: 58-63, 2009.
62. Naguib JM, Kulinskaya E, Lomax CL and Garralda ME: Neuro-cognitive performance in children with type 1 diabetes - a meta-analysis. J Pediatr Psychol 34: 271-282, 2009.

63. Brismar T, Maurex L, Cooray G, Juntti-Berggren L, Lindström P, Ekberg K, Adner N and Andersson S: Predictors of cognitive impairment in type 1 diabetes. Psychoneuroendocrinology 32 : 1041-1051, 2007.

64. Ly TT, Anderson M, McNamara KA, Davis EA and Jones TW: Neurocognitive outcomes in young adults with early-onset type 1 diabetes: a prospective follow-up study. Diabetes Care 34: 2192-2197, 2011.

65. MIS: Reports on Statistical Co-ordination for the Official Statistics of Sweden. SCB, Stockholm, 2002 (In Swedish).

66. Biessels GJ, Deary IJ and Ryan CM: Cognition and diabetes: a lifespan perspective. Lancet Neurol 7: 184-190, 2008.

67. McCrimmon RJ, Ryan CM and Frier BM: Diabetes and cognitive dysfunction. Lancet 379: 2291-2299, 2012.

68. Hannonen R, Komulainen J, Riikonen R, Ahonen T, Eklund K, Tolvanen A, Keskinen P and Nuuja A; Study Group: Academic skills in children with early-onset type 1 diabetes: the effects of diabetes-related risk factors. Dev Med Child Neurol 54: 457-463, 2012.

69. Ryan CM: Why is cognitive dysfunction associated with the development of diabetes early in life? The diathesis hypothesis. Pediatr Diabetes 7: 289-297, 2006.

70. Gonder-Frederick LA,Zrebiec JF, Bauchowitz AU, Ritterband LM, Magee JC, Cox DJ and Clarke WL: Cognitive function is disrupted by both hypo- and hyperglycemia in school-aged children with type 1 diabetes: a field study. Diabetes Care 32: 1001-1006, 2009.

71. Pell GS, Lin A, Wellard RM, Werther GA, Cameron FJ, Finch SJ, Papoutsis J and Northam EA: Age-related loss of brain volume and T2 relaxation time in youth with type 1 diabetes. Diabetes Care 35: 513-519, 2012.

72. Cameron FJ, Scratch SE, Nadebaum C, Northam EA, Koves I, Jennings J, Finney K, Neil JJ, Wellard RM, Mackay M, et al; DKA Brain Injury Study Group: Neurological consequences of diabetic ketoacidosis at initial presentation of type 1 diabetes in a prospective cohort study of children. Diabetes Care 37: $1554-1562,2014$

73. Young V, Eiser C, Johnson B, Brierley S, Epton T, Elliott J and Heller S: Eating problems in adolescents with type 1 diabetes: a systematic review with meta-analysis. Diabet Med 30: 189-198, 2013.

74. Butwicka A,Frisén L,Almqvist C,Zethelius B and Lichtenstein P: Risks of psychiatric disorders and suicide attempts in children and adolescents with type 1 diabetes: a population-based cohort study. Diabetes Care 38: 453-459, 2015.

75. Chen HJ, Lee YJ, Yeh GC and Lin HC: Association of attention-deficit/hyperactivity disorder with diabetes: a population-based study. Pediatr Res 73: 492-496, 2013.

76. McNally K, Rohan J, Pendley JS, Delamater A and Drotar D: Executive functioning, treatment adherence, and glycemic control in children with type 1 diabetes. Diabetes Care 33: $1159-1162,2010$

77. Rydén O, Nevander L, Johnsson P, Westbom L and Sjöblad S: Diabetic children and their parents: personality correlates of metabolic control. Acta Paediatr Scand 79: 1204-1212, 1990. 